\title{
The Effect of The Self-Table Strategy in The Cooperative Method on Learning the Skill of The Puck with Handball
}

\author{
Asst. Inst. Ruqaya Abdul Redha Mohsen AlMousawi, Prof. Dr. Ahmed Khamis Radi AlSudani \\ University of Baghdad / College of Physical Education and Sports Sciences
}

DOI: $10.37648 /$ ijrssh.v10i04.029

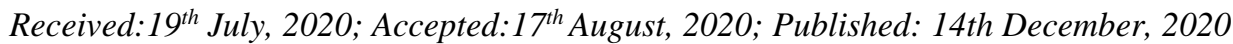

\begin{abstract}
The problem of the research lies in the lack of diversity in the educational methods used, which involve the student in the theoretical and practical side of the subject, the lack of interaction with the teacher, and the reliance on the method of indoctrination of the material from the teacher, with a weakness in the level of thinking, discussion and knowledge area of the skill, as well as the failure to perform some basic skills Hand reel in general and the skill of the tabby in particular in the exact and required form, and therefore the two researchers resorted to solving this problem by using a modern educational strategy that contributes to the optimal use of lessons and the investment of actual learning time for the skill, by knowing the effect of the self-schedule strategy overlapping with the cooperative method on learning some Types of handball skill for students of the second grade average, and the aim of the research was to prepare educational units by applying the self-scheduling strategy by overlapping with the cooperative method of handball for students, and to identify the differences between the pre-post tests for each group in learning some types of the handball skill, and to identify the differences Between the two groups, in the dimensional tests of some types of handball skill, the researchers used the experimental approach with two groups Equivalent (experimentalcontrol) with a pre and post test, as the research community was represented by students of the second stage of the College of Physical Education and Sports Sciences, and from the conclusions reached by the researchers: The use of the self-scheduling strategy in combination with the cooperative method had a positive effect in learning some types of the skill of the kind. The two researchers recommended the necessity of applying the strategy to overlap with methods and stages of study and other mathematical skills.
\end{abstract}

Keywords: self-scheduling strategy, cooperative approach, pooch skills.

\section{INTRODUCTION}

That the learning and teaching process should be based on the activity and activity of the student himself, not on the activity of the teacher alone. Therefore, those in charge of the educational process must use educational strategies and methods that are modern, and contribute to the love of the subject matter, increase acceptance and understanding between individuals and increase cognitive growth, linking and unifying The cognitive aspects of learning in other aspects, and the handball game is one of the fun group games that rely on basic skills as a base on which the game is built to advance the level of performance, so many educational and training methods, strategies and methods that contribute to its learning and acceptance of students are required, so it falls on the teachers' responsibility Diversification by using educational strategies and methods that are compatible with their levels and abilities, which contribute to the delivery of educational material smoothly 
and easily without complication, and to stimulate students and motivate them to work and participate and make them the focus of the learning and teaching process. Learn some types of handball skill, in order to develop uncle The educational mechanism and diversifying it by finding effective educational means or alternatives that stimulate and excite the learner's mind, thus helping to facilitate the reception, storage and retrieval of information.

From the experience of the two researchers as players and teachers in the game of handball, they noted the lack of diversity in the educational methods used that involve the student in the theoretical and practical side of the subject, the lack of interaction with the teacher and the reliance on the method of indoctrination of the material from the teacher, with a weakness in the level of thinking and discussion and the knowledge area of the skill and the law of the game As well as not performing some basic handball skills in general and the skill of the tabby in particular in the exact and required manner, despite the availability of all capabilities of competent teachers with specialization and the prescribed educational curriculum, but that weakness may be due to the failure to use the method that is compatible with the levels of students Therefore, the researchers resorted to solving this problem through the use of a modern educational strategy that contributes to the optimum utilization of lessons and the investment of actual learning time for the skill, and because learning basic handball skills in the second stage is the basis and relying on it for the rest of the school stages, it must be taken care of. From all sides and knowing the effect of the selfschedule strategy using the collaborative method on learning each other Conscious of the handball skill of the tabby for the second stage students.

As for previous studies: The study (Raad Abdullah, 2019) aimed to identify the effect of differentiated learning strategy according to the learning stations method on improving football skills for middle school students, the study sample was represented by middle school students with two control groups that followed the traditional and experimental approach that followed the approach. The educational units with a differentiated learning strategy according to the style of the learning stations and the study showed the effectiveness of the new curriculum and its superiority over the traditional units followed, and the study recommended the necessity of using the strategy according to the method used in middle schools to develop learners for football and other activities, and the need to train teachers on the correct ways to deal with this strategy, and I agreed The current study, along with the previous study, in the use of modern strategies and methods in learning basic skills for sports games, as well as in the experimental approach and the division of the sample (control and experimental), as well as preparing special exercises for the purpose of developing targeted skills according to modern educational methods. The most prominent conclusions and recommendations of the previous study showed the necessity of adopting exercises According to the methods and the Modern educational strategies to enhance the learning process, as there was a positive effect of modern methods and strategies in developing the learning process.

The aim of the study was: To prepare educational units by applying the self-schedule strategy by overlapping with the cooperative method of handball for students of the second stage, and to identify the differences between the pre-post tests for each group in learning some types of handball skill, and to identify the differences between the two groups in the post tests for some Types of handball skill of the subjects of the research sample.

The research hypotheses lie: There are statistically significant differences between the pre and post tests of the two groups in learning some types of handball skill for second-stage students. There are statistically significant differences between the two groups in the dimensional tests of some handball skills of the individuals of the research sample.

\section{MATERIALS AND METHODS:}

The researchers used the experimental approach with two equal groups (experimental-control) with pre and post-test, as the research community was represented by the second stage students of the College of Physical Education and Sports Sciences / University of Baghdad, whose total number is (190) students, divided into (7) divisions, and the researchers selected the two divisions $(\mathrm{A}, \mathrm{C})$ randomly, after which a division (c) would be chosen to represent the experimental group and Division (A) the control group, after the students who had failed and absent were excluded, so that the research sample was made up of (32) students, distributed equally from each Division of (16) students, as the research sample constituted (12.84\%) of the research community, and the exploratory experiment sample

\section{INTERNATIONAL JOURNAL OF RESEARCH IN SOCIAL SCIENCES AND HUMANITIES}


consisted of (6) students from outside the research sample, and the two researchers used the following research methods: observation, Arab and foreign sources, an educational curriculum prepared with the strategy according to The method and skill used, the statistical methods, and the tools used were the playground, goal and hand balls, signs, whistle, metric tape measure and colored adhesive tape. The researchers adopted the vocabulary prescribed for the first semester within the curriculum of the College of Physical Education and Sports Sciences for the second stage of handball subject, including (skill Plump), As a form was prepared to determine the most important tests of the skill of the taboo, and presented to a group of experts and specialists in the topic of the research to find out the suitability of the skill and its tests for the research sample.

Tests used in research for the skill of the puck:

First test: - Continuous ball pad test in a zigzag direction for a distance of (15) (Jamil Qasim and Ahmad Khamis, 2011: 269)

The aim of the test: to measure the skill level of the chick The second test: the continuous test of patience in multiple directions (Jamil Qasim and Ahmad Khamis, 2011: 269)

The aim of the test: to measure the skill of the pug The two researchers conducted an exploratory experiment on (6) students from outside the research sample, as the warm-up was performed and then the tests used in the research were applied, and some exercises used in the educational curriculum were applied, and the purpose of the experiment is to identify the most important difficulties that the two researchers may face when Applying tests and exercises, and ensuring the safety of devices and tools and their suitability for the research sample, and the extent of students' understanding of the tests and exercises.

The main experiment:

Tests before:

The pre-tests were conducted on the research sample in the internal hall of handball at the College of Physical Education and Sciences of Al-Yada / University of Baghdad, as the tests were presented and explained in detail by the researchers to the sample and answer their questions, and the necessary warm-up was performed for them, after which the tests were applied with the help of the assistant work team, For the skill of the students, and the test scores of each student were recorded and filled out in pre-prepared forms for this purpose.

Application of the educational units of the self-schedule strategy in the collaborative manner:

The main experiment of implementing the self-scheduling strategy was implemented in a collaborative manner, which took (8) weeks to implement, according to an educational unit on Monday every week, so that the total number of units was (8) educational units, and the time of one educational unit was (45) minutes, and it was implemented. The Self Schedule Strategy (KWLH) has the following steps:

The subject teacher drew a chart (K.W.L.H) on the blackboard while writing the topic on top of the blackboard. A-The teacher wrote on the board, what do I know about the topic (Know), that is, what do you know about the skill of the pucker with handball

B-The teacher wrote what do I want to learn about the topic (What) i.e. what do you want to know about the skill of the pooch? Then the teacher explained and demonstrated the movement using a PowerPoint presentation, a model for the player, performing the skill with a student, and correcting the mistakes that students make while performing the skill. C- Then the teacher asked what I learned about the topic (Learn) (Using the strategy in conjunction with the cooperative method). The subject teacher explained the skill of the student and presented it to the students and it was applied by the students with exercises according to the cooperative method, and the teacher divided the group into groups, each group consisting of 5 6- Students led by a group leader who collaborate in performing the students 'skill exercises and achieve an achievement in the speed and accuracy of performing these exercises for the students' skill, $y$ there must be cooperation and direction between the students of the group, and the teacher gave feedback and correct the mistakes to the students.

The control group: The subject teacher applied the traditional and accepted approach to the physical education lesson.

D- How can I learn more How: Screenshots of a handball match were watched, and the goal of watching the match is to take notes about the skill of the pupil and present them in the following lectures.

E- The chart was distributed as activity sheets to students to train them in how to fill out the above chart.

Tests after of Research: 
The two researchers conducted the post-tests after completing the application of the educational curriculum with the self-schedule strategy using the collaborative method of hand reel for the research sample, and in the same circumstances in which the pre-tests for the research were conducted, with the same assistant team, and at the time and place in which the pre-tests were conducted.
The statistical means used in the research: The use of appropriate statistical laws to process the data obtained by the researchers from the pre and post tests, through the statistical bag (spss): arithmetic mean, standard deviation, (T) test for linked and unrelated samples.

\section{RESULT AND DISCUSSION:}

Table (1) the values of arithmetic mean, standard deviations, difference of arithmetic means and their deviations in the control group's tests

\begin{tabular}{|l|l|l|l|l|l|l|l|l|l|l|l|}
\hline indication & $\begin{array}{l}\text { mistake } \\
\text { percentage }\end{array}$ & Calculated $\mathrm{P}$ & $\mathrm{P}$ & Test after & & Test before \\
& & & & & $\begin{array}{l}\text { standard } \\
\text { deviation }\end{array}$ & $\begin{array}{l}\text { Arithmetic } \\
\text { mean }\end{array}$ & $\begin{array}{l}\text { standard } \\
\text { deviation }\end{array}$ \\
\hline moral & 0,000 & 8,191 & 0,077 & 0,633 & 0,69 & 11,79 & 0,62 \\
\hline moral & 0,000 & 7,341 & 0,120 & 0,881 & 0,38 & 26,98 & 0,34 \\
\hline
\end{tabular}

Below the level of significance (0.05) and the degree of freedom (15)

Table (1) shows the statistical results in the test of the masters of the control group, which show through the results to the presence of moral differences and in favor of the post-tests, as the researchers attribute the differences to the effectiveness of the method used by the teacher of the subject, which aims to teach students the skill of the discipline, as the educational units Which is prepared in a scientific, studied, varied and correct method that gives good results and achieves the desired goals, and this is confirmed by (Al-Kazemi, 224: 2002), "One of the natural phenomena of the learning process is that there must be an evolution in the learning process as long as the teacher follows the steps and sound foundations for learning and teaching".

Presentation, analysis and discussion of the experimental group results:

Table (2) the values of arithmetic means, standard deviations, difference of arithmetic means and their deviations in the experimental group tests

\begin{tabular}{|l|l|l|l|l|l|l|l|l|l|}
\hline indication & $\begin{array}{l}\text { mistake } \\
\text { percentage }\end{array}$ & Calculated t & P e & P & Test after & Test before \\
\hline moral & 0.000 & & & $\begin{array}{l}\text { standard } \\
\text { deviation }\end{array}$ & $\begin{array}{l}\text { Arithmetic } \\
\text { mean }\end{array}$ & $\begin{array}{l}\text { standard } \\
\text { deviation }\end{array}$ \\
\hline moral & 0.000 & 9,781 & 0,216 & 2,108 & 0,559 & 9,888 & 0,907 \\
\hline
\end{tabular}

Below the level of significance (0.05) and the degree of freedom (15)

Table (2) shows the statistical results in the Al-Tabtba test of the experimental group, which show through the results to the presence of moral differences and in favor of the post-tests, as the researchers attribute the differences to the effectiveness of the strategy by interfering with the cooperative method using exercises prepared in the units that contributed greatly to the development and learning of students' skill Al-Tabtaba for what the educational units contained in terms of displaying the 
vocabulary and explaining it in an adequate manner with pictures and videos, and this is confirmed by (Al-Jubouri and others, 1989: 112), "The educational method that suits the students' abilities and their physical and mental capabilities and that enables the student to choose aspects of the appropriate activity for him, under the supervision and guidance of the teacher It works to achieve the objectives of the lesson. The researcher also attributes the development to the method that was appropriate for the motor skills, and their abilities that contributed to limiting the effort and investment of academic learning time, in addition to the motivation factor and motivation to master the skill and increase the thrill and fun factor in the skill learning process, as well as immediate feedback. For the group members, and this is confirmed (Jaber, 1: 2006), "Strategies are means and mechanisms that help the student to improve his cognitive and physical performance. The effect of its effectiveness in academic achievement and raising its educational efficiency and productivity. "And" The optimal use of the means and methods designed to accomplish scientific and academic tasks successfully and efficiently in the least time and effort "(Al-Nassar, 12: 2006).

Presentation and discussion of the results of the differences between the experimental and control groups in the post-tests:

Table (3) the values of the arithmetic mean and the standard deviations for the two post-tests of the two groups and the value of $\mathrm{t}$ calculated in the tests of the skill of the punch

\begin{tabular}{|l|l|l|l|l|l|l|l|}
\hline indication & Sig & Calculated t & Control group & Experimental group & the exams \\
& & & $\begin{array}{l}\text { Standard } \\
\text { deviation }\end{array}$ & $\begin{array}{l}\text { Arithmetic } \\
\text { mean }\end{array}$ & $\begin{array}{l}\text { standard } \\
\text { deviation }\end{array}$ & $\begin{array}{l}\text { Arithmetic } \\
\text { mean }\end{array}$ \\
\hline moral & 0.000 & 8,574 & 0,69 & 11,79 & 0,559 & 9,888 & $\begin{array}{l}\text { The } \\
\text { test } 1\end{array}$ \\
\hline moral & 0.000 & 9,349 & 0.38 & 26,98 & 0,666 & 25,194 & $\begin{array}{l}\text { The } \\
\text { chuck } \\
\text { test } 2\end{array}$ \\
\hline
\end{tabular}

Below the level of significance (0.05) and the degree of freedom (30)

\section{CONCLUSIONS:}

Table (3) shows the statistical parameters of the two groups (control and experimental) in the post-tests in the research variables, and the results show the presence of significant differences in favor of the experimental group, and the researchers attribute the differences to the effectiveness of the strategy with the cooperative method using exercises prepared in the units, which contributed greatly to the development and learning Students' skill and fixation of the correct movement path when performing, as well as the theoretical aspect applied during the strategy that was more appropriate with the cooperative method in terms of ease and understanding of performance requirements during the educational unit, and confirmed by (Al-Hashemi and AlDulaimi, 154: 2008) "The set of steps and practices Which the teacher follows within the educational unit, helps him achieve the objectives of the course, and includes many elements (the introduction to the lesson to raise the motivation of the pupils, determine and follow up the educational activities, the time allocated to each of them, the type of interaction that may occur within the educational unit, and the method that the teacher will follow in order to help him achieve The objectives of the course). The exercises used within the educational unit contributed greatly to these results, as they are very similar to technical performance. And the ideal skill for students, because the stability of the skill performance of the learner requires a lot of repetition and continuous error handling, which in turn enhances the student's confidence and motivates him to continue and learn more.

\section{ENDORSEMENT:}

From the conclusions reached by the researchers, the use of the self-schedule strategy in conjunction with the cooperative method had a positive effect on learning some types of the students 'skill, the use of exercises prepared in the cooperative method led to 
the learning and development of the skill of the students, and among the recommendations was the application of the strategy that overlaps with methods and stages of study and other mathematical skills.

\section{REFERENCES:}

- Jaber Abdul-Hamid and others, University Study Skills, Saudi Arabia, King Saud University Press, 2006.

- Jamil Qassem and Ahmad Khamis; The International Handball Encyclopedia, 1st Edition, Lebanon, Dar Al-Safa for Publications, 2011.

- Raad Abdullah Kadim; the effect of differentiated learning strategy according to the method of learning stations in improving football skills for middle school students, a master's thesis, Al-Mustansiriya University, College of Basic, Education, Department of Physical Education 2019.

- Saleh Abdul-Aziz Al-Nassar; a degree that enables King Saud University students to study skills and their needs from the viewpoint of the students themselves and faculty members at the university, a study published in the Journal of the Institute for Research and Revival of Islamic Heritage, Kingdom of Saudi Arabia, King Saud University, 2006.

- Diaa Al-Khayyat, Nawfal Muhammad Al-Hayali; Handball, Mosul, Dar Al-Kutub for Printing, 2001.

- Zafer Hashem Al-Kazemi: Interdisciplinary teaching style and its effect on learning and development through spatial organizational options for the tennis. education environment, PhD thesis, University of Baghdad, College of Physical Education, 2002

-Abd al-Rahman al-Hashemi and Taha Ali Hussain al-Dulaimi, Modern Strategies in Teaching, Amman, Sunrise House, 2008 -Adnan Al-Jubouri and two others; Methods of Teaching Physical Education and Kinetic Learning, Iraq, Dar Al-Kutub, 1989

\section{ANNEX (1)}

Some exercises for the skill of the co-operative

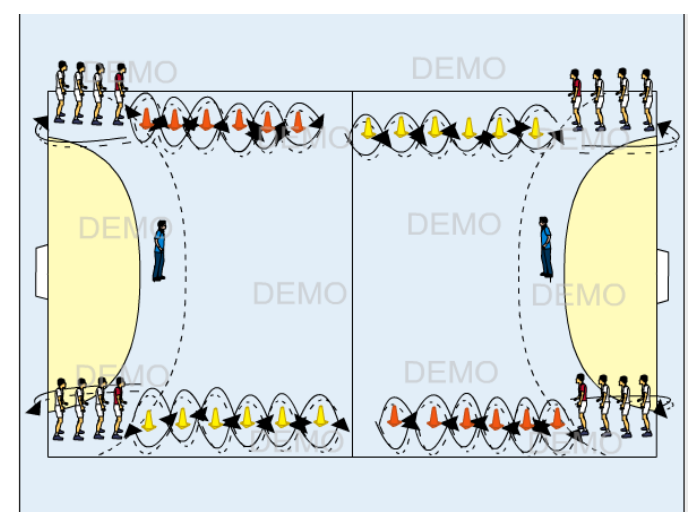

Exercise No. (1)

The name of the exercise: - the continuous and zigzag chopping between the faces back and forth

How to perform the exercise: - The first student from each group starts after hearing a beep

The teacher and the performance of the winding and continuous strumming between the signs back and forth and the distance between the signs is a halfmeter, then return to the starting point of the tabba and stand to the end of the group and each group has a leader who leads it to consult among them about performing the exercise and repeating the exercise

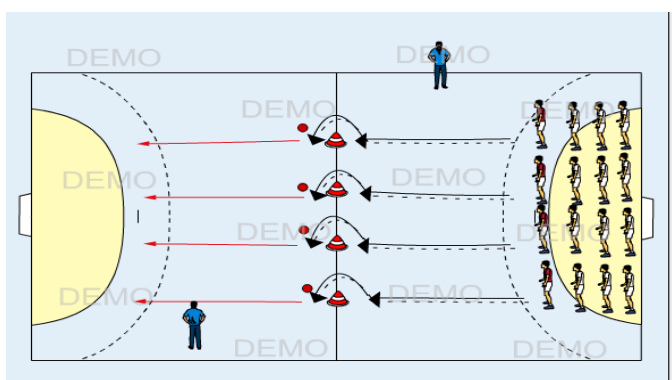

Exercise No. (2)

Exercise name: - continuous chucking in the middle of the field The method of performing the exercise: - The group stops at the 6-meter line and the first student from each group starts after hearing the teacher's whistle and the continuous performance of the piling to the center line, turning around the person, leaving the ball on the ground and completing the exercise, running to the end of the stadium 

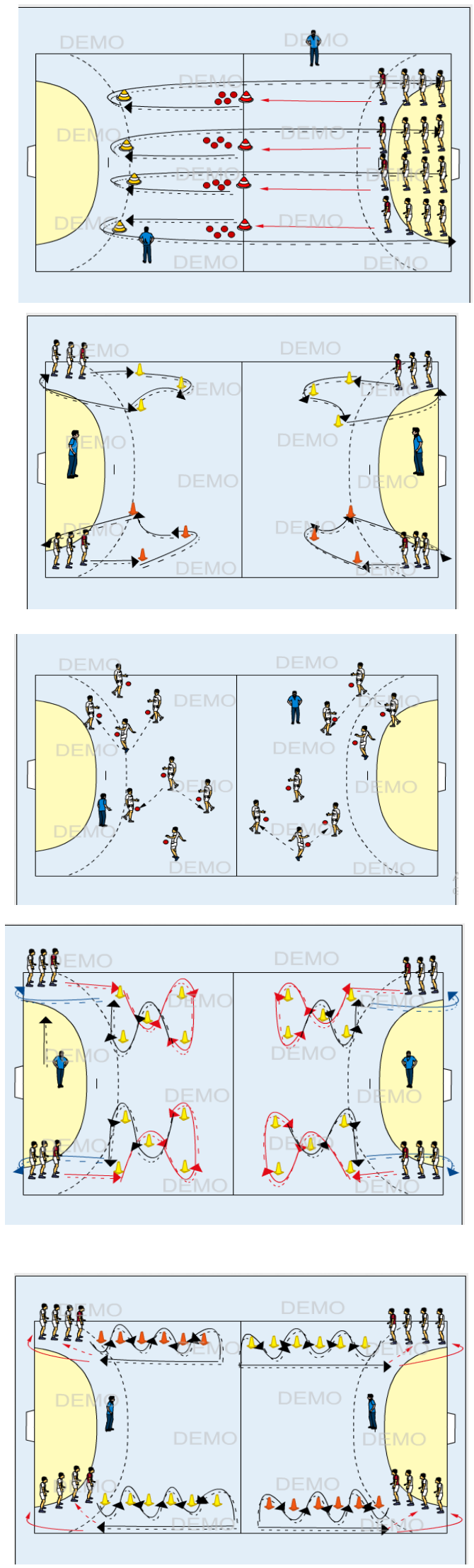

Exercise No. (3)

Exercise name: - The continuous chuckling after the midfield line The method of performing the exercise: - The group stops at the 7-meter line and the first student from each group starts after hearing the teacher's whistle and runs without a ball to the center line and takes the ball placed on the ground there and runs with the continuous pad to the 9-meter line and turns around the person and returns with the continuous padding to the starting point and standing behind the group

Exercise No. (4)

The name of the exercise: - The winding chute between the halves in front of the $9 \mathrm{~m}$ area

The method of performing the exercise: - Each group stands in the corner area of the stadium and there are 3 signs in the form of a triangle in front of the nine-meter line, the distance between the heads is 3 meters, and the first student starts after hearing the whistle from the teacher and doing the zigzag between the halves and back to the end of the group

\section{Exercise No. (5)}

Exercise name: - The constant choking of standing in place The method of performing the exercise: - The students are divided into two groups, each group stands in a circle to do the continuous churning in the place from standing and upon hearing the whistle the ball is handled and rotated to the classmate in a pre-agreed direction, either to the right or left

\section{Exercise No. (6)}

Exercise name: - The curly chuck between the faces The method of performing the exercise: - Each group stands in the corner area of the stadium and there are 5 foursquare-shaped and the fifth in the center of the square, the distance between the signs is 3 meters, and the first student starts after hearing the whistle from the teacher and doing the zigzag in the form of two circles adjacent to the halves and back to the end of the group

\section{Exercise No. (7)}

Exercise name: - Exercise continuous and zigzag tapping between faces

The method of performing the exercise: - The first student from each group starts after hearing the teacher's whistle and performing the winding and continuous rolling between the signs and the distance between the signs is one and a half meters, then returning to the starting point with the continuous choping and handling the ball to the colleague standing after him and returning and standing to the end of the group 


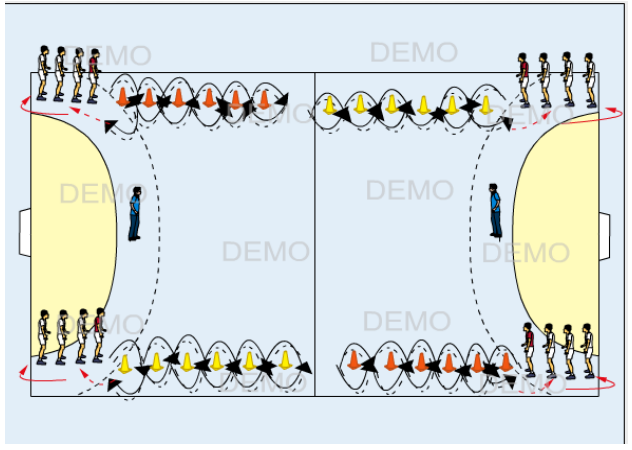

\section{Exercise No. (8)}

The name of the exercise: - the continuous and winding chucking between the faces back and forth

The method of performing the exercise: - The first student from each group starts after hearing the teacher's whistle and performing the winding and continuous strumming between the signs back and forth, and the distance between the signs is one and a half meters, then returning to the starting point with the continuous and winding chops between the signs and handling the ball to the colleague standing at the beginning of the group and back and standing at the end of the group

A model for an educational unit

Stage: Second - Division: C today and date: // 2019

Educational goal: To accustom students to the love of cooperation and order during the lesson. Number of students: 16 students

Educational objective: Teaching the skill of the potting. Unit instruction time: 90 minutes 


\begin{tabular}{|l|l|l|l|l|}
\hline Notes & Educational unit content & Time & $\begin{array}{l}\text { Sections of the } \\
\text { educational unit }\end{array}$ & sequence \\
\hline & & $15 \mathrm{~m}$ & $\begin{array}{l}\text { Preparatory } \\
\text { department }\end{array}$ & 1 \\
\hline
\end{tabular}

$5 \mathrm{~m} \quad$ General preparation

A video of the research sample was shown about the skill of the puck and its importance with handball

This step helps refine ideas about writing and reading information, and helps increase thinking about how to perform, when to perform puckering, and what mistakes students make

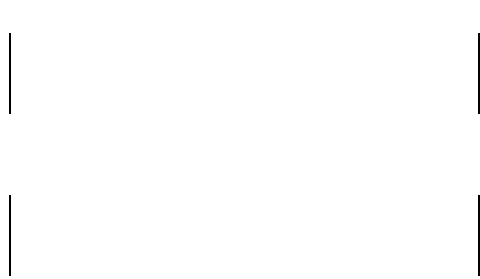

Homework

\begin{tabular}{|l|l|}
$10 \mathrm{~m}$ & Special preparation \\
$60 \mathrm{~m}$ & The main section
\end{tabular}

Applying a strategy for self- $3 \mathrm{~m}$ scheduling: The first stage know: asking students a question, what do you know about the skill of the students? The second stage what: the teacher asks a question (What do you want to know about the skill of the students?) Here, the skill of the students is explained and demonstrated with the Model Power Point. Explanations with the answer and the correction of the answer by the teacher with a repeat of the presentation: ask the students, what did you know about the skill of the pupils?

The application of exercises using the cooperative method

\begin{tabular}{|l|l}
$15 \mathrm{~m}$ & The educatio \\
$3 \mathrm{~m}$ & \\
$10 \mathrm{~m}$ & \\
$5 \mathrm{~m}$ & \\
& \\
$40 \mathrm{~m}$ & Application \\
\hline $10 \mathrm{~m}$ & Exercise 1 \\
$10 \mathrm{~m}$ & Exercise 2 \\
$10 \mathrm{~m}$ & Exercise 3 \\
$10 \mathrm{~m}$ & Exercise 4
\end{tabular}

The application of the last stage: How: ask students what is the importance of the skill of the pettiness, when it is used, and what do you want to learn more

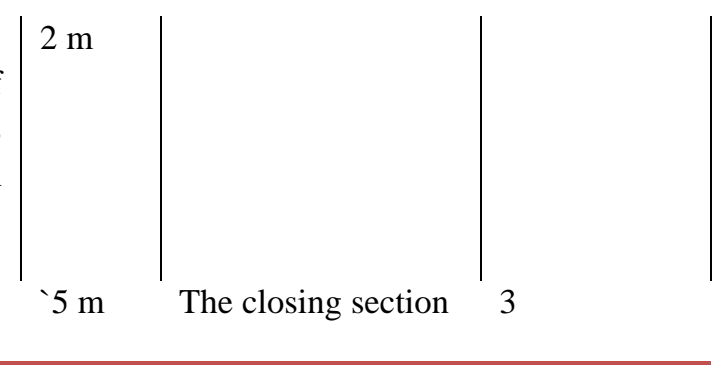

